\title{
THE THEORY OF LIGHT.
}

The Theory of Light. By Thomas Preston, M.A., Lecturer in Mathematics and Mathematical Physics, University College, Dublin. London and New York, Macmillan \& Co., 1890. 8vo.

UNTIL within a very few years it has been a matter of considerable difficulty for American students interested in higher theoretical optics to pursue this study with advantage, for want of access to the original memoirs and the absence of any adequate presentation of their contents in any of the American text-books. For the students of the English universities, Airy's Undulatory Theory of Optics and Loyd's Wave Theory of Light have been the chief English helps until the publishing of Glazebrook's admirable Physical Optics. It has been a great pity that the clear and beautiful presentation of the subject given by President Barnard in 1862, and printed in the Smithsonian Report for that year, was not long since published in separate book form, as it would be to-day one of the very best books on the subject were it printed in a form accessible to college students having a fair command of elementary mathematics. I hare been greatly surprised to find it so little known oven among American students who have made a special study of the higher optics in European universities. Besides the English books referred to above, the admirable report of Professor Stokes on Double Refraction in the British Association Report for 1862, and the equally admirable later one on Optical Theories by Glazebrook in 1865, together with such books as Beer's Introduction to Higher Optics, Knochenhauer's Undulatory Theory of Light, Lord Rayleigh's articles in the Encyclopædia Britannica and the Philosophical Magazine, Verdet's Lecons d'Optique Physique, Poincaré, Briot, Sir William Thomson, and Professor Tait have heretofore supplied the special advanced student with most of his needs. It has been very desirable, however, that a treatise should be written for English-speaking students, similar to those which Verdet and Poincaré have written for the French, dealing both with profound theory and experimental facts. This seems to have been done by Professor Preston of Dublin.

The work in some respects resembles Verdet's Optique Physique. It begins, however, from a more elementary basis, and includes the more recent work of Lord Ravleigh and Professors Rowland and Hertz. In this latter respect as well as in some others, it is better than Glazebrook's Physical Optics. It lacks the splendid bibliography of Verdet, and is on the whole much more elementary. 
It begins with the simplest principles of wave motion, treated both with and without mathematics. The difference between wave and group velocity is explained at the end of chap. II. after the manner of Lord Rayleigh's Sound. Huygens's principal and secondary waves are well explained, and Stokes's law of the intensity of the light at any point of a secondary wave is given together with a reference to his celebrated paper on the Dynamical Theory of Diffraction, 1849. At the end of chap. IV., explaining reflection upon the wave theory, we have this admirable remark: "In dealing with problems in the reflection of light we may therefore consider the light propagated in rays if it facilitates the solution. Yet we must carefully bear in mind that rays have no physical existence, for it is waves that are propagated and not rays." (The italics are ours.) In chap. V., in discussing the energy equation, the density of the ether is referred to as "that property of it which corresponds to the density of ordinary matter, and by which it possesses energy when in motion." We have here a hint of ether inertia that may be due to other causes than mere mass, e. g. rotatory inertia. The chapter on determination of refractive indices, gives a very full account of the usual methods, with references to the original memoirs. The section on gases is particularly good.

Chap. IX. is on diffraction, and it is at this point that the really mathematical part of the book may be said to begin. The treatment is clear and thorough, and nothing is slurred over that can possibly help a student to a competent understanding of the subject, although the treatment sometimes seems a little too concise. So vast is the ground covered, however, that this seems almost a necessity.

This is the only book so far as we know which gives a pretty full discussion of the theory and use of Rowland's concave gratings and an account of the new determination of wave lengths by Rowland and Bell.

The entire treatment of diffraction is very full and satisfactory, although the remarkable results of Lord Rayleigh and Professor Michelson on the distribution of the light from sources other than points are not given. Cornu's graphical methods of dealing with diffraction problems however are quite fully given. The recent applications of these researches of Rayleigh and Michelson to spectroscopy could hardly have had a place in the book, which has been out of press for more than a year.

An admirable but brief presentation of the views of MacCullagh and Neumann on the relation of the plane of vibration to the plane of polarization in polarized light, is given, together with the different suppositions involved as to the changes of density and rigidity of the ether in crystals on 
which diverse views on this point are founded. One might wish that some of these more purely physical or dynamical questions had been discussed at greater length. Reference is however made to the admirable report of Glazebrook on optical theories in the British Association Report for 1885. The papers of Sir William Thomson, Willard Gibbs, Ketteler, and Glazebrook, in the Philosophical Magazine, American Journal of Science, and Wiedemann's Annalen, since that time, however, are particularly important, especially the extraordinary speculation of Sir William Thomson on a "labile" ether and Willard Gibbs' able discussion of the same. The notion of a medium capable of transmitting transverse vibrations in virtue of a quasi-rigidity imparted to it by motion, especially rotatory motion, is evidently becoming more and more important and Sir William Thomson, although apparently still an adherent of the elastic solid theory, has himself shown how the rotation of the plane of polarization in a magnetic field can be explained by the assumption of such an ether. In the last chapter (XXI.) the author of this treatise has given a sketch, clear and as simple as the nature of the subject will allow, of the present state of the electro-magnetic theory of light and the experimental researches of Dr. Hertz on electro-magnetic waves. Oliver Heaviside has done so much work in this direction that it seems as if some mention might have been made of it. So also Professor Rowland.

The whole treatment of the subject of polarized light is full and satisfactory, while, on the whole, also very concise.

There are a large number of examples added to éach chapter. These are well selected and the sources indicated from whence they are derived. The advanced student has thus pointed out to him what authorities on each part of the subject may be best for him to consult. One of the very best features of the book, in our opinion, is the impression it leaves on one's mind of its being, above all, an able, clear, and accurate presentation of the subject as it was left by Fresnel - the Newton of the undulatory theory of light. As Fresnel left it, so, except that Maxwell and Lorenz have shown that the vibrations are probably electro-magnetic in character, it essentially is to-day. Questions as to the ultimate structure and constitution of the ether are related to the undulatory theory of light, just as questions as to the mechanism of gravitation are to the theory of gravitation, as ordinarily treated. The ordinary mathematical theory and its confirmation by observation and experiment, rest intact, no matter what may prove to be the physical mechanism by which their results are brought about. The famous Baltimore lectures of Sir William Thomson, the British Association reports 
(1862 and 1885) of Stokes and Glazebrook, and the later papers alluded to before, are the natural sources of information for those who wish to go into these matters.

For advanced students in colleges and all who wish to acquire a thorough knowledge of the existing state of the undulatory theory of light, we recommend this admirable treatise. The type and illustrations are also models of clearness and elegance and reflect credit upon the publishers as well as the author.

UNIVERSITY OF WISCONSIN,

Madison, October 12, 1891.

JoHN E. DAVIES.

\section{NOTES.}

A regular meeting of the New York Mathematical SocieTY was held Saturday afternoon, November \%, at halfpast three o'clock, the vice-president in the chair. 'The following persons having been duly nominated, and being recommended by the Council, were elected to membership: Professor Simon Newcomb, Navy Department and Johns Hopkins University; Dr. Oskar Bolza, Clark University; Mr. Charles Riborg Mann, Columbia College; Professor Ludovic Estes, University of North Dakota ; Mr. Herbert Armistead Sayre, Montgomery, Alabama; Professor James Harrington Boyd, Macalester College; Dr. Asaph Hall, Jr., U. S. Naral Obșervatory ; Dr. Percy F. Smith, Yale University ; Mr. Edwin H. Lockwood, Yale University; Professor Robert Judson Aley, Indiana University ; Professor Joseph V. Collins, Miami University ; Dr. Charles H. Chapman, Johns Hopkins University; Professor Albert Munroe Sawin, University of Wyoming; Mr. Frank Gilman, Lowell, Massachusetts ; Professor Henry Parker Manning, Brown University ; Mr. Oharles S. Peirce, Milford, Pennsylvania.

Mr. Charles P. Steinmetz read an original paper entitled "On the curves which are self-reciprocal in a linear nul-system, and their configurations in space."

Dr. Edward L. Stabler made some remarks upon the theory of errors which are equally probable between given limits.

THE nul-system in space, which formed the subject of $\mathrm{Mr}$. Steinmetz's paper, is a one-to-one correspondence between points and planes such that any point lies in its conjugate plane, and conversely. A linear nul-system is one in which all the planes conjugate to the points of any straight line 